http://www.jfas.info

\title{
INFLATABLE STRUCTURE FOR AEROSPACE APPLICATION: HISTORICAL PERSPECTIVE AND FUTURE OUTLOOK
}

\author{
N. A. Dollah*, M. R. Saad and A. CheIdris \\ Faculty of Engineering, UniversitiPertahananNasional Malaysia, Sg. Besi Camp, 57000 Kuala \\ Lumpur, Malaysia
}

Published online: 10 September 2017

\begin{abstract}
This is an overview topic of inflatable structure for aerospace application. An inflatable structure is a promising choice for a wide range of aerospace application. Among the application are inflatable wing, space antenna, solar array, inflatable aeroshell and inflatable aerodynamic decelerators. The advantages of inflatable structure are it offers the potential for compact stowing of lightweight structure. This will result in low storage volume, lightweight, efficient packaging, easy to deploy and ultimately lead to reduction in mission cost. Historically, inflatable technology has been introduced as a concept in aerospace application with a patent on flying glider that uses inflatable tubular segments connected to the fuselage. Over the years, many concepts of inflatable were introduced but only a small number of concepts have progress beyond the stage of design and even fewer manage to be completed and used extensively.
\end{abstract}

Keywords: inflatable structure material; unmanned aerial vehicle (UAV); aerospace application.

Author Correspondence, e-mail: noorazman@upnm.edu.my

doi: $\underline{\text { http://dx.doi.org/10.4314/jfas.v9i3s.26 }}$ 


\section{INTRODUCTION}

Inflatable structures are made by joining flexible composites membrane materials into an enclosed volume [1]. There are many advantages of inflatable structure compared to conventional structures. Among them are inflatable structure can be packaged into small volume, have low mass and also low manufacturing cost [2-6]. There are a wide range of potential applications of inflatable structures in the field of aerospace such as aerodynamics decelerators, antenna, solar arrays, reflector arrays,inflatable wings for UAV, kiteplane and others [6-8]. In this section, the historical perspective and the current development of several type of inflatable structure in aerospace application are reviewed.

\subsection{Inflatable Wing}

An inflatable wing structure was first proposed by Taylor Daniel in 1930. He patented his flying glider that uses inflatable tubular segments connected to fuselage. However, due to lack of practical usage, his invention went largely unnoticed despite its unbeatable safety records. In 1950s, Goodyear Aircraft Company invented a fully inflatable aircraft for the purpose of army rescue vehicle that could be dropped behind enemy lines [9]. When fully inflated, the aircraft measures about 6.7 meter in wing span and 6 meter by length and once deflated, it could be packed into a 1.25 -meter cube container. In the $1970 \mathrm{~s}$, ILC Dover introduced the first UAV that utilizes inflatable wing design. It was promoted to be stowable and compact for ease of portability, but despite successful flight testing, it was never put into production [10]. The concept of gun-launched UAV can be seen from the development of Forward Air Support Munition (FASM) and Gun Launched Observation Vehicle (GLOV) by the US military [11]. The UAVs were designed to sustain high dynamic loads to meet the requirement of deploying their wing at apogee for maximum endurance flight. The X-24A by NASA also using the inflatable wing technology to reduce landing speed on lifting body [9]. Defense Advanced Research Projects Agency (DARPA) together with ILC Doveralso develop and tested a rocket-launched inflatable UAV that can be deployed and launch within minutes to perform intelligence, surveillance, reconnaissance and communication missions [12]. 


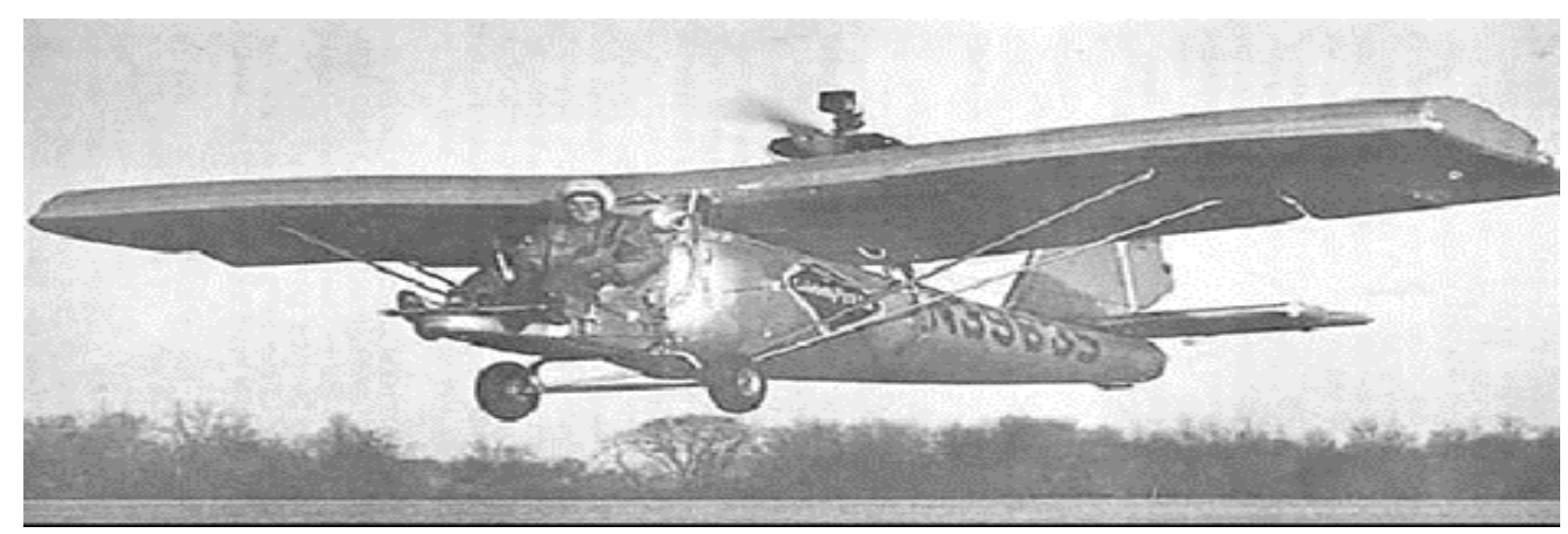

Fig.1. Goodyear Inflatoplane [9]

In the past decade, researchers from University of Kentucky under the BIG BLUE project has been the leading team in the research on inflatable wing. Numerous test including structural testing and wind tunnel testing to determine the aerodynamic behavior during flight has been made. They also done computational study and flight test of the UAV with inflatable wing [13-22]. However, after a successful flight test, there are lack of further development towards this research afterwards.

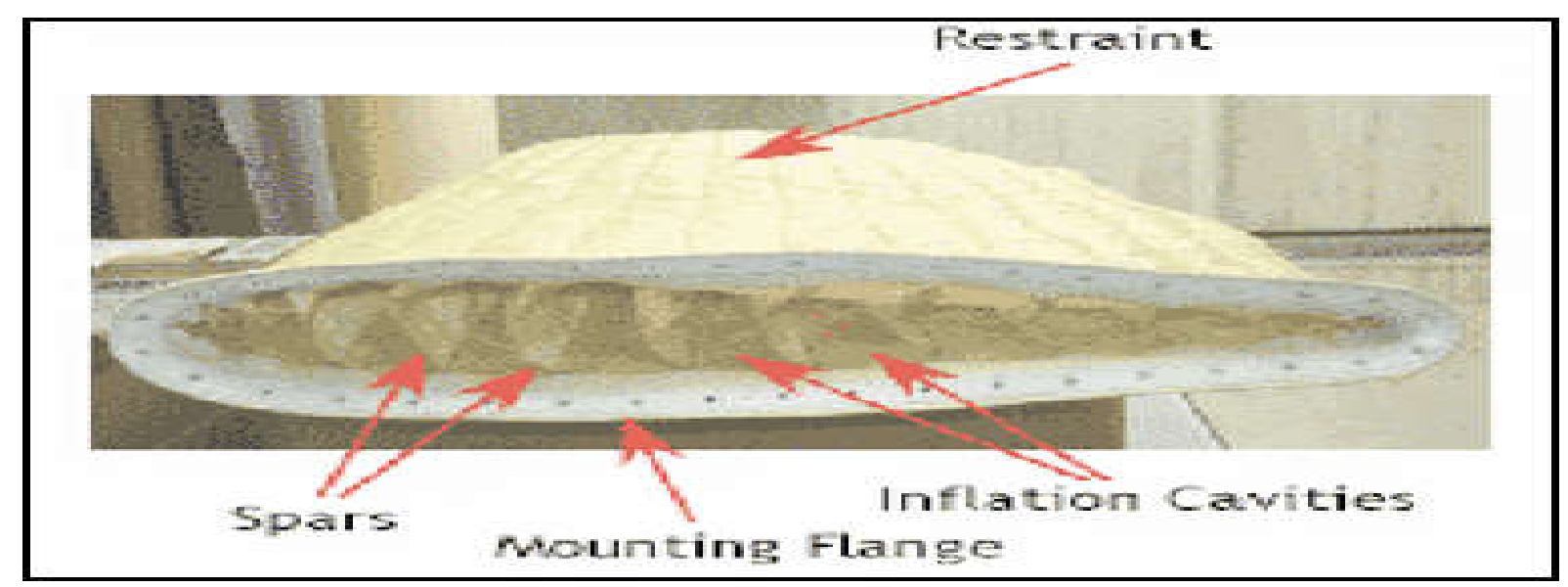

Fig.2. Structure of inflatable wing [13]

There are two main concepts of inflatable wing that has been widely developed. The first concept that has been used in several research is inflatable wing that requires constant pressurization once it inflated [13]. The advantage of this concept is it is simpler but there will be additional component which is the pressure regulator in the inflation system to maintain the pressure in the wing during flight, and there is also the possibility to be punctured. The other concept is inflatable rigidizable wing where the wing will be rigidizing once it fully inflated by means of using resin [21]. This concept of UAV using rigidize wing has reduced 
the possibility of punctured, but the problem is inflatable rigidizable wing can only be used once since it cannot be deflated.Once it being rigidize, this make it less attractive in term of manufacturing cost.

In summary, the inflatable wing as a concept has been around for years but it was not translated into a practical application. However, due to the needs of current crop of UAV that require compact storage and quick launch mechanism, there is a need to further explore the capability of inflatable wing technology. The prospect of inflatable wing has also risen as this concept has been one of the methods of choice for morphing wing technology [23-25].

\subsection{Inflatable Aerodynamics Decelerators (IAD)}

The concept of IAD is first proposed in the 1960 s by NASA and it function as a decelerator by increasing a vehicle's drag area [26]. Aerodynamic decelerators are important for planetary exploration vehicles. It will function asa decelerator to minimize the descent rate, provide stability during re-entry process and protect the vehicle from impact during landing [27-28]. Its capability to being deployed at higher dynamic pressures and Mach numbers is the advantages of IAD over the conventional parachute technology as these abilities will result in significantly increasing deceleration [26].

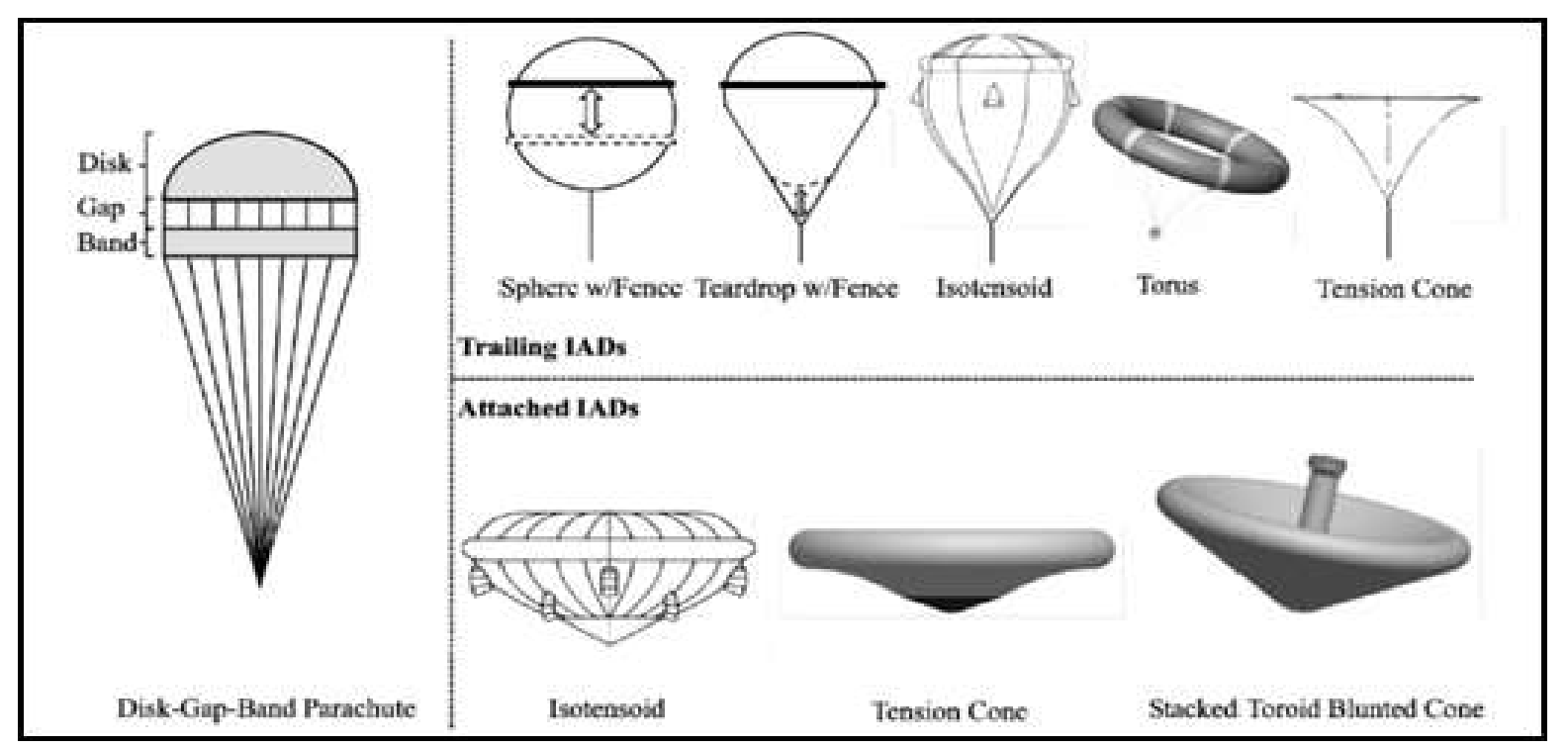

Fig.3.Several type of IAD [26]

Numerous researches and testing were conducted on the IAD. One of them is on whether the IAD is capable to perform as a precision-enhancing device for the purpose of pinpoint the landing of the vehicle or payload [27]. Research by [8] focuses on effect of the internal 
inflation and aerodynamic load towards the fabric. Other researches also include the investigation of the static analysis of the IAD, also stability and aerodynamic behavior of the decelerator at various inflation pressures and under different flow conditions [29-30].

\subsection{Inflatable Antenna and Solar Array}

Antenna reflector is important in many space missions and it needs a large size antenna reflector to enhance its efficiency. However, there is a limit to the size of the reflector due to the constraint in the payload of the launch vehicle. This constraint can be overcome using a new type of space antenna using inflatable technology [5].

Since successfully launch and deploy a 14 meter diameter inflatable offset parabolic reflector in 1996, NASA has continued its study on concepts and technologies for long-life space mission supported by large rigidizable structure [3]. Other researchers also study the static and dynamic behaviour of inflatable parabolic structures under various inflation pressures [31]. The inflatable solar array is another structure that benefits from inflatable technology. The inflatable solar array (ISA) has many advantages over the traditional structure and the current development of the ISA is summarizing in [32].

\subsection{Other Type of Inflatable Structure}

In [33] has developed an inflatable kiteplane, which has the same design of a conventional sail plane. The structure of the kiteplane consists of the main wing, which is made by a membrane material and the leading edge that is formed by an inflatable tube.

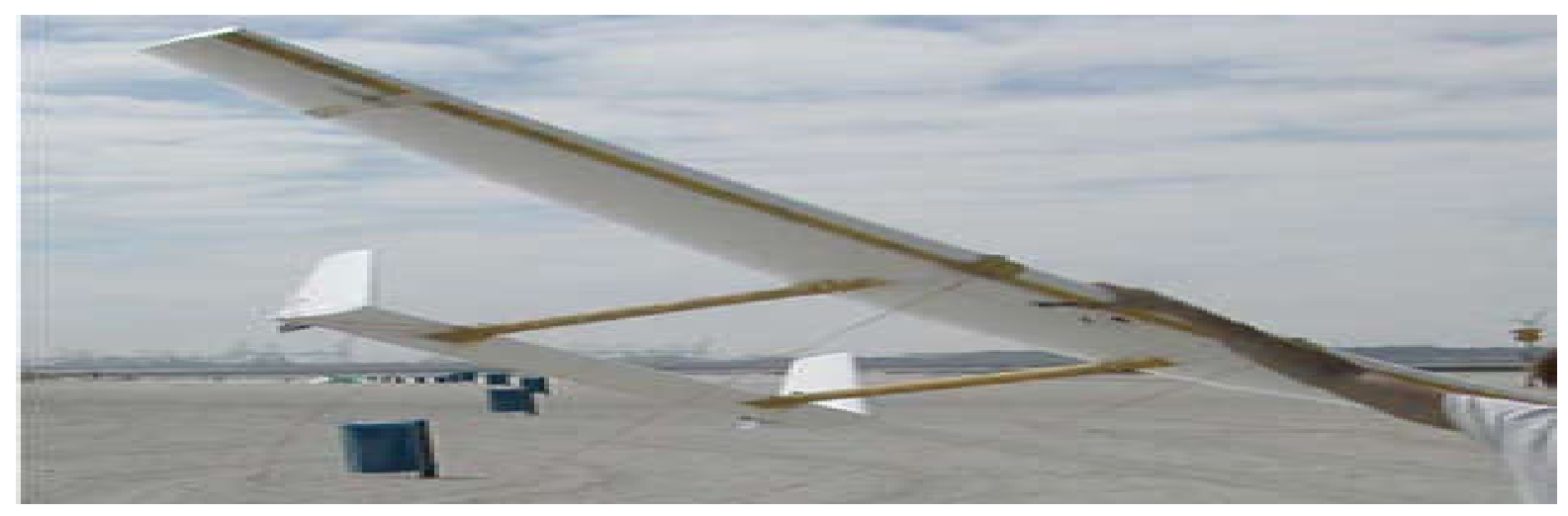

Fig.4. Scale model of inflatable kiteplane [33]

Research has also been done to adapt the basic changeable elements from nature's heliotropism and turn it into a smart adaptive structure called the Self-inflating Adaptive Membrane (SAM). An experiment was developed in order to validate the different inflation 
deployment techniques in space conditions [4]. These are the examples of inflatable technology that has been used in a wide range of aerospace application. Even with low Technology Readiness Level (TRL), it is still being the topic of many research interest. This is mainly due to its advantage of offering a lightweight solution that was very crucial in the aerospace environment.

\section{MATERIALS}

Material that are suitable for inflatable structure are high strength, flexible material that can withstand the pressure load. ILC Dover which is a company that has been involved in many inflatable structures in collaboration with NASA and other research institutions has done a review of different materials that can be applied to inflatable structure [34].Based on their finding, the most suitable material for inflatable structure are flexible materials namely Ultra-High-Molecular-Weight Polyethylene (UHMWPE) such as Dyneema and Spectra; Aramid such as Kevlar, Twaron,Technora; Liquid Crystal Polymer (LCP) such as Vectran; Poly(p-phenylene-2,6-benzobisoxazole) (PBO) such as Zylon; and fiberglass such as S-glass. UHMWPE is one of the strongest fabrics and much lighter than other material, but fabrication of inflatable structure using this material could be quite difficult [35]. By comparing according to specific modulus versus specific strength, PBO is the best material. However, PBO is rarely used due to the cost of the material that was significantly higher than other material. Fiberglass especially the S-glass also has a large tensile strength, but its disadvantage is the high specific gravity makes it unsuitable for application that requires lightweight structure. Other examples of material used for inflatable structures are Kapton, Twaron and Dacron. However, materials like Kapton, Dacron and Twaron even though they have good performances in terms of tensile strength, the setback is their costs are very high [36]. 
Table 1. Properties of suitable material for inflatable structure [10]

\begin{tabular}{|c|c|c|c|c|c|c|}
\hline Material & 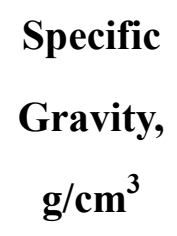 & $\begin{array}{l}\text { Cost, } \\
\text { \$/lb }\end{array}$ & $\begin{array}{c}\text { Yarn } \\
\text { Tenacity, } \\
\text { g/den }\end{array}$ & $\begin{array}{c}\text { Tensile } \\
\text { Strength, } \\
\text { x } \mathbf{1 0}^{\mathbf{3}} \text { psi }\end{array}$ & $\begin{array}{c}\text { Tensile } \\
\text { Modulus, } \\
\text { x } 10^{6} \text { psi }\end{array}$ & $\begin{array}{l}\text { Strain to } \\
\text { Failure, \% }\end{array}$ \\
\hline \multicolumn{7}{|c|}{ Spectra/Dyneema } \\
\hline -Dynema & 0.97 & 23 & 40 & 507 & 16 & 3.5 \\
\hline -900 UHMW PE & 0.97 & 23 & & 375 & 17 & 3.5 \\
\hline -1000 UHMW PE & 0.97 & 29 & 32 & 435 & 25 & 2.7 \\
\hline \multicolumn{7}{|c|}{ Vectran } \\
\hline$-\mathrm{HS}$ & 1.41 & $22-90$ & 23 & 412 & 9.4 & 3.3 \\
\hline$-\mathrm{M}$ & 1.4 & 15 & 9 & 161 & 7.6 & 2 \\
\hline \multicolumn{7}{|c|}{$\mathrm{PBO}$} \\
\hline$-\mathrm{AS}$ & 1.54 & 110 & 42 & 840 & 26 & 3.5 \\
\hline$-\mathrm{HM}$ & 1.56 & 110 & 42 & 840 & 39 & 2.5 \\
\hline \multicolumn{7}{|c|}{ Kevlar } \\
\hline -49 Aramid Fiber & 1.46 & 25 & 23 & 420 & 9.8 & 2.5 \\
\hline -29 Aramid Fiber & 1.46 & $15-40$ & 23 & 420 & 12 & 3.6 \\
\hline -689 Aramid Fiber & 1.46 & $15-40$ & & 420 & $25-26$ & \\
\hline -149 Aramid Fiber & 1.55 & 25 & 18 & 340 & 21 & 1.45 \\
\hline \multicolumn{7}{|c|}{ Technora } \\
\hline$-\mathrm{T}-240$ & 1.45 & $15-30$ & 28 & 414 & 15.8 & 4.4 \\
\hline \multicolumn{7}{|c|}{ Fiberglass } \\
\hline -S-glass & 2.49 & 5.5 & 21 & 665 & 13.5 & 5.7 \\
\hline -E-glass & 2.6 & 0.85 & 15.1 & 500 & 12.4 & 4.8 \\
\hline \multicolumn{7}{|c|}{ Graphite/Carbon } \\
\hline -HS Pan & $1.7-1.8$ & 20 & 21.3 & $410-580$ & $33-36$ & $2-2.5$ \\
\hline -UHS Pan & $1.7-1.8$ & 20 & 31.3 & $590-830$ & $38-42$ & 1.8 \\
\hline -HM Pan/Pitch & $1.8-2.0$ & 20 & 14.2 & $250-500$ & $50-80$ & 0.4 \\
\hline -UHM Pitch & $2.0-2.2$ & 20 & 11.9 & $300-360$ & $90-130$ & 0.3 \\
\hline
\end{tabular}


Therefore, only Aramid (Kevlar and Technora) and LCP (Vectran) remain as the most suitable material for inflatable wing application and the proof that these material are the best is the fact that many research group on inflatable structure are using either of this material for their research [23, 27, 37-42].

Between these two materials, there is not much difference in term of the mechanical properties of both materials. Vectran has better flex-crack/abrasion resistance which means that when a fabric is folded, Vectran fibers are less damaged compared to Kevlar. However, Kevlar has the advantage that it offers higher strength retention at higher temperatures [43]. The main advantage of Kevlar over Vectran is it is slightly lower in cost and available in a wide range of weaves. Kevlar is also well-known technology and has many worldwide suppliers in comparison to Vectran, which only has one international supplier [10,44].

The main problem of Kevlar and Vectran fiber are they are very sensitive to ultraviolet (UV) irradiation. Structure using these materials is vulnerable to serious photo degradation effect on the fibers. Thus, they both have to be protected if used in normal daylight. Several researches has demonstrated that the UV durability of Kevlar fibers can be significantly improved by coating nanostructured $\mathrm{TiO}_{2}$ film to improve the resistance of Kevlar fibers from UV radiation. Beside successfully improve the resistance, analysis done also show that mechanical performance of $\mathrm{TiO}_{2}$ coated fibers is much better than that of uncoated one after exposing to UV light [45]. The testing of UV protective layer for high strength fiber using $\mathrm{TiO}_{2}$ also show that there is significant drop of the effect of degradation on the coated fiber compared to the uncoated fiber [46].

\section{FABRICATION}

Inflatable structure usually comprise of two main layer of material. The outer layer is very important as these layer offer protection and need to withstand all the load. The inner layer functions as a bladder that retains the gas. Due to their function, outer layer usually is made from high strength fiber such as Kevlar and Vectran while the material for inner layer is from material that have high gas retention capability such as PE or PU film.

The main fabrication techniques for inflatable structures are heat sealing for the inner layer 
and stitching for the outer layer. For the inner layer, heat sealing would be the best option to create seams to join the materials. However, as the sample is fabricated by hand, it was difficult to create even seams around all edges. The problem of this method is because the strength depends on the quality of the seal. Therefore, a more automated process would help solve the problem and it will also contribute to a much quicker manufacturing times.

Stitching is the method to fabricate the outer layer of the inflatable structure. The material from high strength fiber will be stitched with high tenacity thread [15-18].

A new technique of fabrication for inflatable structure that will use flexible impermeable material silicon to fabricate the inflatable wing fabricated integrally with a lattice structure as reinforcement. The lattice structure serves two purposes, the first is to provide the inflatable wing its shape and the second is to absorb a portion of the load exerted on the wing [47].

\section{TESTING METHOD}

The design and prototype of inflatable structure that is under development need to be tested to determine its performance and capability. The testing of inflatable structure can be categorized into the experimental method and computational analysis. The focus of the testing is to determine the structural analysis and aerodynamic analysis of the inflatable structure.

\subsection{Experimental Method}

1) Static load: A static load test was developed to verify the structural analysis and the inflatable structure geometry when subjected to a static pressure load. The method of testing is different between different types of inflatable structure. For inflatable aeroshell, the structure was placed on a hydraulic ram and surrounded by metal tub. The displacements were measured using string potentiometers and laser scanning [48]. For static load testing of inflatable wing, the deflection is measured for point load at wing tip, distributed loading pattern and wing twist. The testing was done for different forces and different inflation pressure to test the response of the wing at each parameter [49]. 


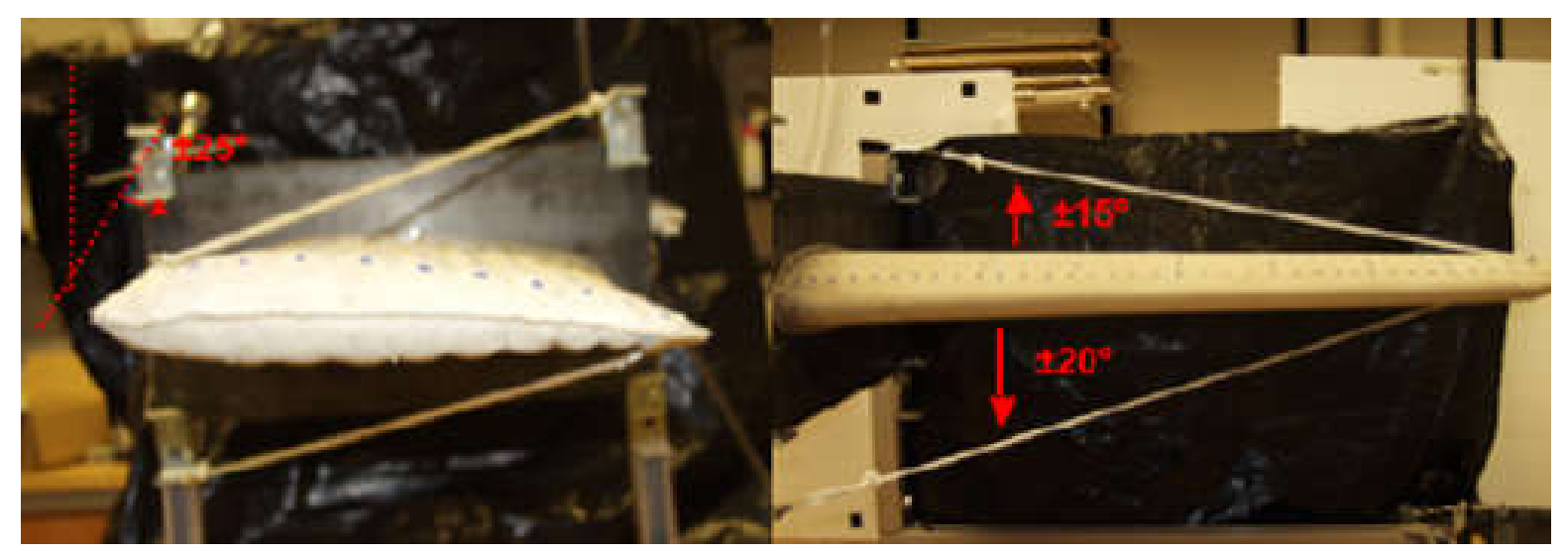

Fig.5. Wing twist set-up [49]

2) Wind tunnel: The aeroelastic behavior of the inflatable structure is determined by wind tunnel testing. It is important to get the value of the aerodynamic coefficient of the model and to determine whether the wing exhibit undesirable deformation during flight such as twist or bending. Many testing has been done in low-speed wind tunnel. Due to the size of the wing, it was mounted vertically in the test section of the wind tunnel. For the sequence of tests performed, only lift and drag forces were analyzed. The range of parameter such as the angle of attack and the Reynolds numbers is varied for different research [50]. Most of the wind tunnel testing is done with the help of photogrammetry. Photogrammetry is preferred for inflatable wing because it is a non-intrusive technique where only markers are being marked on the surface of the wing. High resolution camera will take multiple digital images of the wing during the test and the image will be combined and process to generate a 3D representation of the wing surfaces [49]. Research to determine the response of IAD to dynamic pressure has also been done. The sensitivity to inflation pressure was also determined to ensure the system can operate at the most optimum inflation pressure [51].

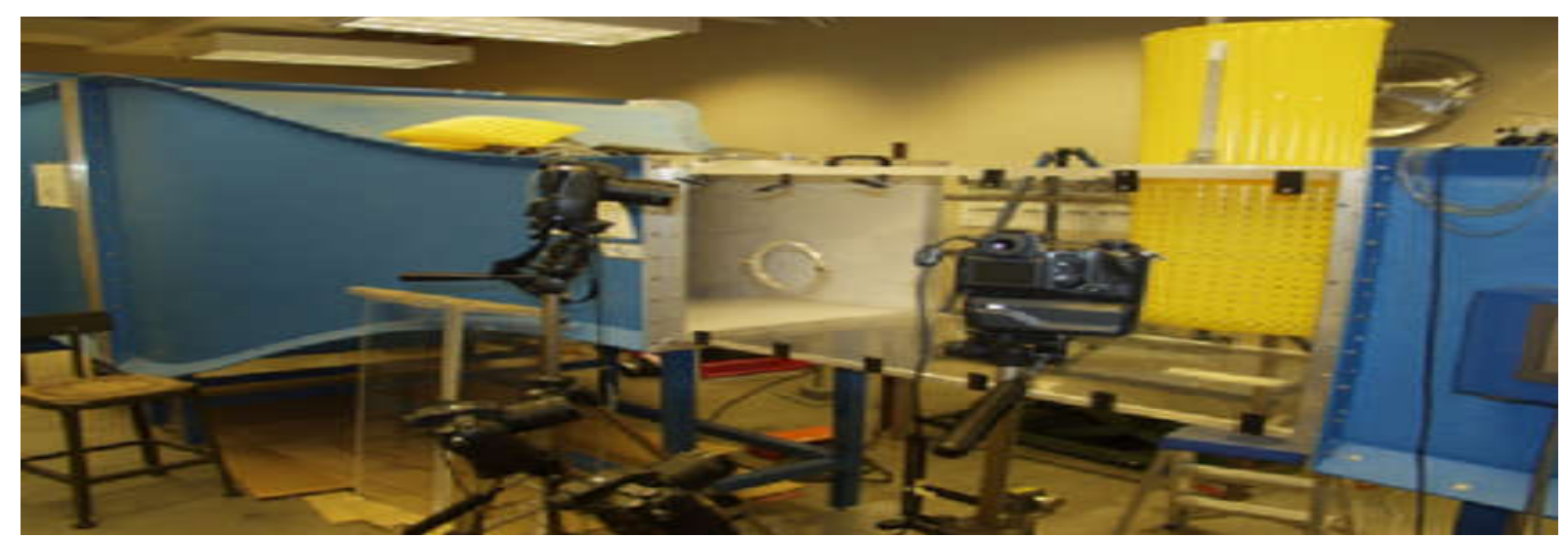

Fig.6. Wind tunnel test set-up [49] 


\subsection{Computational Analysis}

In order to analyze the structural and aerodynamic performance of the inflatable structure, simulation needs to be done. However, it is not an easy task to do simulation on the inflatable structure because it involves a lot of variables to be considered. There is several software that is widely used in aerospace sector to model an inflatable structure such as LS-DYNA, ANSYS, ABAQUS and NASTRAN. Each of them has its own advantages.

With the advancement in the field of computational analysis, Finite Element Analysis (FEA) is becoming more important in the analysis of inflatable structure. Computational analysis has been able to perform the complex flow environment and it also has the ability to perform analysis in different disciplines simultaneously to provide more accurate simulations.

For the simulation on inflatable wing, normally it is done in two steps. First, the internal pressure is applied to the surface of the model and then external loading are applied with the stress-stiffening effect from the pressure loading included.

One of the software that is usually used for finite element analysis (FEA)is LS-DYNA. Since the inflatable structure has something in common with an airbag in term of inflation and fabric material, a look into the computational analysis of airbag is also considered. In LS-DYNA, the keyword AIRBAG is used to simulate the thermodynamic behavior of the gas flow into the airbag as well as a reference configuration for the fully inflated bag. Several researches on inflatable structure have used LS-DYNA especially the research on IAD. The analysis includes the process of deployment of the inflatable structure [52] or to perform FEA on IAD under static loading condition and to validate the result measured from the experiment $[48,53-55]$.

Another software preferred for the computational analysis of inflatable wing are ANSYS. The BIG BLUE team that develop a big scale project on inflatable wing used ANSYS for the analysis. A study to determine the maximum stress expected for a rigidizable wing is done using ANSYS Linear Layer Structural Shell Element SHELL99 and the material is assumed to be an isotropic material [21]. Meanwhile, a FEA analysis was done on an inflatable wing to validate the result from the experimental testing. A linear orthotropic material model was used for the model and the shell element is SHELL181 [16]. 
Among the different software's that are being used for the computational analysis of inflatable wing, LS-DYNA can be considered as the preferred choice among many researchers. LS-DYNA has also shown to be extremely robust and produces the most consistent solution for membrane like material which is the material that was used for the inflatable structure [29].

\section{OUTLOOK FOR THE FUTURE}

In addition to the current advancement of composite materials, it is known that carbon nanotubes (CNT) are theoretically one of the strongest and stiffest materials. The potential of using CNT as fillers in polymer composites has shown a very promising prospect. Kevlar is one of the polymers that could benefit from the addition of CNT to produce an ultra-high strength material [56-57]. The effect of the enhancement of the Kevlar polymer by the CNT is the product made from the CNT reinforced Kevlar can have a very high strength without the extra weight added to it. This exceptional mechanical property is very important in the development of inflatable wing. Using this lighter material without compromising the strength of the end product has open the possibility for the development of a high speed UAV application.

From another perspective, there are also the possibility of using this inflatable technology in Mars. The atmosphere in Mars that can only accommodate low Reynolds number means that exploration aircraft to be used in Mars need a very large wing to provide enough lift [21, 58]. However, large wing is not economically and structurally practical. Therefore, inflatable wing has been proposed as an alternative where helium gas will be used to inflate the wing and it will provide extra lift through buoyancy effect.

\section{CONCLUSION}

This review is done on the inflatable structure focusing on their aerospace applications. The area of research in this technology is so wide and this paper only focuses on the material, fabrication and testing method that has been done over the years. Even though many research has been done and the inflatable structure has already been used especially in aerospace sector, 
there are still a lot to be done. Currently, the level of research in inflatable structure technology is still not at an acceptable level and not fully developed yet. Further testing of the inflatable structure should also be done to fully understand the behavior of the inflatable structure. The fabrication technique could be further improved to enhance the construction of the inflatable structure. Further improvement especially in the field of material will certainly contribute to the enhancement of the inflatable structure. With the progressive development in the research of the inflatable structure technology, this inflatable technology is going to be a very promising technology for aerospace application.

\section{REFERENCES}

[1] Xu Y J, Zeng P, Lei L P. Investigation of shape retention of inflatable structures based on experiments and fluid-structure interaction analysis. Applied Mechanics and Materials, 2014, 457:581-584

[2] Freeland R, Bilyeu G, Veal G, Steiner M, Carson D. Large inflatable deployable antenna flight experiment results. ActaAstronautica, 1997, 41(4):267-277

[3] Noor A K, Venneri S L, Paul D B, Hopkins M A. Structures technology for future aerospace systems. Computers and Structures, 2000, 74(5):507-519

[4] Sinn T, Vasile M, Tibert G. Design and development of deployable self-inflating adaptive membrane. In 53rd AIAA/ASME/ASCE/AHS/ASC Structures, Structural Dynamics and Materials Conference, 2012, pp. 1-10

[5] Xu Y, Guan F. Structure design and mechanical measurement of inflatable antenna. ActaAstronautica, 2012, 76:13-25.

[6] Xiao W, Chen W, Fu G. Wrinkle analysis of the space inflatable paraboloid antenna. Journal of Shanghai Jiaotong University (Science), 2011, 16(1):24-33

[7] Walker S J, McDonald A D, Niki T, Aglietti G S. Initial performance assessment of hybrid inflatable structures. ActaAstronautica, 2011, 68(7):1185-1192

[8] Li L, Gonyea K C, Braun R D. Finite element analysis of the inflatable re-entry vehicle experiment. In 56th AIAA/ASCE/AHS/ASC Structures, Structural Dynamics and Materials Conference, 2015, pp. 1-13 
[9] Norris R K, Pulliam W J. Historical perspective on inflatable wing structures. In 50th AIAA/ASME/ASCE/AHS/ASC Structures, Structural Dynamics, and Materials Conference, 2009, pp. 2139-2145

[10] Cadogan D, Graham W, Smith T. Inflatable and rigidizable wings for unmanned aerial vehicles. In 2nd AIAA "Unmanned Unlimited"Infotech@AerospaceConference, 2003, pp. $6624-6630$

[11] Brown G, Haggard R, Norton B. Inflatable structures for deployable wings. In 16th AIAA Aerodynamic Decelerator Systems Technology Conference, 2001, pp. 21-24

[12] Cadogan D, Scarborough S, Gleeson D, Dixit A, Jacob J, Simpson A. Recent development and test of inflatable wings. In 47th AIAA/ASME/ASCE/AHS/ASC Structures, Structural Dynamics and Materials Conference, 2006, pp. 1-4

[13] Rowe J, Smith S, Simpson A, Jacob J. Preliminary modal analysis of inflatable wings. American Institute of Aeronautics and Astronautics, 2006, 27(3):11-23

[14] Simpson A, Jacob J, Smith S. Aerodynamic control of an inflatable wing using wing warping. In AIAA 35th Fluid Dynamics Conference, 2005, pp. 6-9

[15] Usui M, Jacob J, Smith S, Scarborough S, Cadogan D. Second generation inflatable/rigidizable wings for low-density flight applications. In 46th AIAA/ASME/ASCE/AHS/ASC Structures, Structural Dynamics and Materials Conference, 2005, pp. 18-21

[16] Rowe J M, Smith S W, Simpson A, Jacob J, Scarborough S. Development of a finite element model of warping inflatable wings. In AIAA Gossamer Spacecraft Forum, 2006, pp. $1-4$

[17] Simpson A, Smith S W, Jacob J. Aeroelastic behavior of inflatable wings: Wind tunnel and flight testing. In 45th Aerospace Sciences Meeting, 2010, pp. 1-22

[18] Jacob J D, Simpson A, Smith S. Design and flight testing of inflatable wings with wing warping. In SAE Technical Paper, 2005, pp. 205-210

[19] Simpson A, Rowe J, Smith S W, Jacob J. Aeroelasticdeformation and buckling of inflatable wings under dynamic loads. In 48th AIAA/ASME/ASCE/AHS/ASC Structures, Structural Dynamics, and Materials Conference, 2007, pp. 2230-2239 
[20] Simpson A, Jacob J, Smith S. Flight control of a UAV with inflatable wings with wing warping. In 24th Applied Aerodynamics Conference, 2006, pp. 1-19

[21] Usui M, Simpson A, Smith S, Jacob J. Development and flight testing of a UAV with inflatable rigidizable wings. In 42nd AIAA Aerospace Sciences Meeting, 2004, pp. 6-10

[22] Kearns J D, Usui M, Smith S W, Scarborough S, Smith T, Cadogan D. Development of UV-curable inflatable wings for low-density flight applications. In 45th AIAA/ASME/ASCE/AHS/ASC Structures, Structural Dynamics and Materials Conference, 2004, pp. 1498-1503

[23] Cadogan D, Smith T, Uhelsky F, MacKusick M. Morphing inflatable wing development for compact package unmanned aerial vehicles. In 45th AIAA/ASME/ASCE/AHS/ASC Structures, Structural Dynamics and Materials Conference, 2004, pp. 1-13

[24] Barbarino S, Bilgen O, Ajaj R M, Friswell M I, Inman D J. A review of morphing aircraft. Journal of Intelligent Material Systems and Structures, 2011, 22(9):823-877

[25] Chattopadyay N, Jony G, Acharya A. An analysis on wing morphing. Global Science and Technology Journal,2015, 3(1):41-51

[26] Smith B P, Tanner C L, Mahzari M, Clark I G, Braun R D, Cheatwood F M. A historical review of inflatable aerodynamic decelerator technology development. In IEEE Aerospace Conference, 2010, pp. 1-18

[27] Miller M J, Steinfeldt B A, Braun R D. Investigation of drag-modulated supersonic inflatable aerodynamic decelerators for sounding rocket payloads. Journal of Spacecraft and Rockets, 2015, 52(2):383-392

[28] Cruz J R, Lingard J S. Aerodynamic decelerators for planetary exploration: Past, present, and future. In AIAA Guidance, Navigation, and Control Conference, 2006, pp. 21-24

[29] Bopp M S, Ruffin S M. A loosely coupled analysis of the fluid-structure interactions for inflatable aerodynamic decelerators. In 51st AIAA Aerospace Sciences Meeting including the New Horizons Forum and Aerospace Exposition, 2013, pp. 1-13

[30] Kramer R, Cirak F, Pantano C. Fluid-structure interaction simulations of a tension-cone inflatable aerodynamic decelerator. AIAA Journal, 2013, 51(7):1640-1656

[31] Dipan Y S, Upadhyay S, Harsha S. Vibration analysis of inflatable parabolic structure for 
space application. In ASME International Design Engineering Technical Conferences and Computers and Information in Engineering Conference, 2012, pp. 873-877

[32] Cui D, Yan S, Guo X, Chu F. An overview of dynamics modeling of inflatable solar array. Energy Procedia, 2012, 14:1967-1972

[33] Breukels J, Ockels W. Design of a large inflatable kiteplane. In 48th AIAA Structures, Structural Dynamics and Materials Conference, 2007, pp. 1-10

[34] Hinkle J, Lin J, Kling D. Design and materials study of secondary structures in deployable planetary and space habitats. In 52nd AIAA/ASME/ASCE/AHS/ASC Structures, Structural Dynamics, and Materials Conference, 2011, pp. 1-10

[35] Edge H L, Brown A, Collins J. Pressurized structures-based unmanned aerial vehicle research. Journal of Intelligent and Robotic Systems, 2012, 65(1):603-620

[36] Ruocco P, Romano P, De Fenza A, D’Orazio D, Barile M, Lecce L. Development of a finite element model for inflatable winglet. In XXII AIDAA National Congress, 2013, pp. 1-12

[37] Butt L M, Kurdi M H, Kapania R K, Asheghian L. Aeroelasticanalysis and optimization of a rigid/inflatable wing. In 52nd AIAA/ASME/ASCE/AHS/ASC Structures, Structural Dynamics and Materials Conference, 2011, pp. 1-31

[38] Jones T C, Doggett W R. Time-dependent behavior of high-strength Kevlar and Vectran webbing. In 55th AIAA/ASME/ASCE/AHS/SC Structures, Structural Dynamics, and Materials Conference, 2014, pp. 1-22

[39] Kenner W S, Jones T C, Doggett W R, Lucy M H, Grondin T A, Whitley K S, Duncan Q, Plant J V. Long term displacement data of woven fabric webbings under constant load for inflatable structures. In 55th AIAA/ASME/ASCE/AHS/SC Structures, Structural Dynamics, and Materials Conference, 2014, pp. 1-30

[40] Litteken D, Selig M, Valle G, Oliveras O. Utilizing photogrammetry and strain gage measurement to characterize pressurization of an inflatable module. In 53rd AIAA/ASME/ASCE/AHS/ASC Structures, Structural Dynamics and Materials Conference, 2012, pp. 1-16

[41] Smith B P, Clark I G, Braun R D. Thermal, structural, and inflation modeling of an 
isotensoid supersonic inflatable aerodynamic decelerator. In IEEEAerospace Conference, 2011, pp. 1-16

[42] Smith S W, Jacob J D, Jones R J, Scarborough S E, Cadogan D P. A high-altitude test of inflatable wings for low-density flight applications. In 7th AIAA Gossamer Spacecraft Forum, 2006, pp. 1-13

[43] Cadogan D, Sandy C, Grahne M, Development and evaluation of the mars pathfinder inflatable airbag landing system. ActaAstronautica, 2002, 50(10):633-640

[44] Hori K, Hoshino Y, Shimizu H. Vectran: Development of high-functionality fiber and its $\begin{array}{lllll}\text { applications } & \text { at } & \text { Kuraray } & \text { Ctd. }\end{array}$ https://hermes-ir.lib.hit-u.ac.jp/rs/bitstream/10086/26905/1/070iirWP14-06.pdf

[45] Chen W, Qian X, He X, Liu J. Enhanced ultraviolet resistance of Kevlar fibers with $\mathrm{TiO}_{2}$ films. In 9th IEEE International Conference on Reliability, Maintainability and Safety, 2011, pp. $1267-1272$

[46] Won J, Said M A, Abdel-Fattah M S. Development of UV protective sheath for high performance fibers for high altitude applications. Fibers and Polymers, 2013, 14(4):647-652

[47] Tan Y E, Moon S K. Inflatable wing design for micro UAVs using indirect 3D printing. In 11th IEEE International Conference onUbiquitous Robots and Ambient Intelligence, 2014, pp. 545-546

[48] Jurewicz D, Brown G, Gilles B, Lichodziejewski L, Kelly C, Tutt B, Hughes S. Design and development of inflatable aeroshell structure for IRVE-3. In 21st AIAA Aerodynamic Decelerator Systems Technology Conference, 2011, pp. 1-10

[49] Simpson A, Coulombe N, Jacob J, Smith S. Morphing of inflatable wings. In46th AIAA/ASME/ASCE/AHS/ASC Structures, Structural Dynamics and Materials Conference, 2005, pp. 1-11

[50] Ghobadi K J, Pifer E, LeBeau Jr R P, Bramesfeld G, McQuilling M. A computational and experimental investigation of flow over an inflatable wing. In 30th AIAA Applied Aerodynamics Conference, 2012, pp. 1-12

[51] Kazemba C D, Cassell A M, Kushner L K, Tran K, Quach B T, Li L, Van Norman J W, Littell J D, Johnson R K, Hughes S J. Determination of the deformed structural shape of 
HIADs from photogrammetric wind tunnel data. In 22nd AIAA Aerodynamic Decelerator Systems Technology Conference, 2013, pp. 1-14

[52] Liu J, Sun S, Bai S. Bio-inspired design of an inflatable deployable structure. In IEEE International Conference onCyber Technology in Automation, Control, and Intelligent Systems, 2015, pp. 994-999

[53] Hill J L, Braun R D. Explicit finite element analysis of inflatable braided strapped beams. In 23rd AIAA Aerodynamic Decelerator Systems Technology Conference, 2015, pp. 1-9

[54] Hill J L, Braun R D. Implementation of a mesomechanical material model for IAD fabrics within LS-DYNAltextregistered. In AIAA Aerodynamic Decelerator Systems Conference, 2013, pp. 1-16

[55] Hutchings A L, Braun R D, Masuyama K, Welch J V. Experimental determination of material properties for inflatable aeroshell structures. In 20th AIAA Aerodynamic Decelerator Systems Technology Conference and Seminar, AIAA, 2009, pp. 1-24

[56] Sainsbury T, Erickson K, Okawa D, Zonte C S, Fréchet J M, Zettl A. Kevlar functionalized carbon nanotubes for next-generation composites. Chemistry of Materials, 2010, 22(6):2164-2171

[57] O’Connor I, Hayden H, O'Connor S, Coleman J N, Gun'ko Y K. Polymer reinforcement with kevlar-coated carbon nanotubes. Journal of Physical Chemistry C, 2009, 113(47):20184-20192

[58] DeSouza C. Conceptual design of an unmanned aerial vehicle for mars exploration (MISCAV). In 44th Lunar and Planetary Science Conference, 2013,pp. 1-2

\section{How to cite this article:}

Dollah N A, Saad M R, CheIdris A. Inflatable structure for aerospace application: historical perspective and future outlook. J. Fundam. Appl. Sci., 2017, 9(3S), 317-334. 